\title{
HIGIENE MENTAL INFANTIL Y PSICOANÁLISIS EN LA CLÍNICA DE CONDUCTA, SANTIAGO DE CHILE, 1936-1938
}

\author{
Silvana Vetö \\ Facultad de Humanidades y Ciencias Sociales / Universidad Andrés Bello. \\ silvana.veto@gmail.com \\ ORCID iD: http://orcid.org/0000-0002-4970-9702
}

Recibido: 07 abril 2017; Aceptado: 08 junio 2017.

Cómo citar este artículo/Citation: Vetö, Silvana (2017), "Higiene mental infantil y psicoanálisis en la Clínica de Conducta, Santiago de Chile, 1936-1938", Asclepio 69 (2): p195. doi: http://dx.doi.org/10.3989/asclepio.2017.18

\begin{abstract}
RESUMEN: Tomando en cuenta la importancia del estudio situado en historia de las ciencias, en este artículo se explora una temprana iniciativa de higiene mental infantil en Chile que aun no ha sido abordada por la literatura especializada: la Clínica de Conducta, fundada en Santiago en 1936 como parte de la Escuela Especial de Desarrollo, la cual había sido creada por la Reforma Educacional de 1928. La Clínica de Conducta puso en marcha un programa estatal de higiene mental infantil que incluía como referencia central al psicoanálisis, en un periodo en que no era habitual encontrarlo en la bibliografía médica local. Se analizará aquí el contexto de creación de estos servicios, así como los modos en que la higiene mental y el psicoanálisis fueron apropiados y utilizados en una institución cuyo principal interés no era la defensa o legitimación de una teoría, sino el abordaje de problemáticas sociales como la delincuencia y la educación infantil. Aparecen así algunas características de la historia de los saberes psi en Chile, mostrando cómo se despliegan en el escenario de problemáticas sociales y cómo se vinculan con el devenir de otras disciplinas y prácticas como la criminología y la pedagogía.
\end{abstract}

PALABRAS CLAVE: Higiene Mental; Psicoanálisis; Infancia; Clínica de Conducta; Chile.

\section{CHILD MENTAL HYGIENE AND PSYCHOANALYSIS AT THE CLINIC OF CONDUCT, SANTIAGO DE CHILE, 1936-1938}

ABSTRACT: Taking stance in a situated perspective, this article looks into one of the first Chilean state initiatives aimed at the study and care of child psyche. This institution that has not yet been explored by specialized literature: the Clinic of Conduct, founded in the city of Santiago in 1936 as part of the Special School of Development, which was created in the context of a the Educational Reform of 1928. The Clinic of Conduct launched a state managed mental hygiene programme that included psychoanalysis as its main reference at a time when psychoanalysis was not yet a regular reference in the local medical world. We are thus interested in analysing context in which this initiatives were created and the ways in which mental hygiene and psychoanalysis were appropriated and used in an institution in which the principal interest was not the defence or legitimation of a singular theory, but the approach to specific social problems such as child delinquency and education. Some characteristics of the history of psy knowledges in Chile emerge from this study, showing how they unfold on the scenario of social problems and how they relate to other disciplines and practices such as criminology and pedagogy.

KEY WORDS: Mental Hygiene; Psychoanalysis; Childhood; Clinic of Conduct; Chile.

Copyright: (c) 2017 CSIC. Este es un artículo de acceso abierto distribuido bajo los términos de la licencia Creative Commons Attribution (CC BY) España 3.0. 


\section{INTRODUCCIÓN}

Abordar la historia de la salud mental infantil en Chile no parece ser tarea fácil. ${ }^{1}$ Las fuentes y la historiografía son escasas, mientras que las exigencias presentes son urgentes y diversas. ${ }^{2}$ En este artículo intentaremos abordar una de las primera iniciativas chilenas de salud mental infantil. Más específicamente, pretendemos describir y analizar la forma en que la higiene mental y el psicoanálisis fueron apropiados, utilizados y entremezclados en la Clínica de Conducta, fundada en 1936 como parte de la Escuela Especial de Desarrollo, creada en 1928 por una radical reforma educacional llevada a cabo ese año durante la dictadura de Carlos Ibáñez del Campo (1927-1931). Para entender cómo el psicoanálisis se insertó en este programa de higiene mental infantil, es necesario primero situar la Clínica de Conducta en el contexto de las transformaciones de comienzos de siglo XX en materia de educación y los cambios culturales y sociales referidos a la infancia. ${ }^{3}$ Con ese objetivo, abordaremos primero algunas de las transformaciones ocurridas en Chile en las primeras décadas del siglo $X X$ respecto del modo en que se entendía la infancia y la adolescencia, plasmándose hacia la década de 1920 en diversas legislaciones que apuntaron a la protección, educación y reeducación de los niños, niñas y adolescentes. Posteriormente, nos detendremos en las reformas que hacia 1928 llevaron a la fundación de la Escuela Especial de Desarrollo, en la cual se alojó luego la Clínica de Conducta. Después de ello, desarrollaremos algunas ideas referidas a la higiene mental en Chile, para terminar indagando en las intersecciones entre higiene mental y psicoanálisis Ilevadas a cabo la Clínica de Conducta entre 1936 y 1938.

\section{INFANCIA Y ADOLESCENCIA EN CHILE HACIA 1920}

La creación de la Escuela Especial de Desarrollo y de la Clínica de Conducta, así como de otras instituciones y prácticas relativas a la protección de la infancia en Chile, deben ser entendidas en el contexto de los efectos que tuvieron en América Latina las transformaciones ocurridas entre las décadas de 1880 y de 1920 en Estados Unidos y Europa respecto de la forma de entender y abordar la infancia y la adolescencia.

Estas transformaciones -que no abordaremos aquí en detalle-, se dejan sentir fuertemente en Chile en la nueva legislación que dominará desde 1929 el abordaje de la infancia y la adolescencia bajo el término "menores", plasmándose en referencias, conceptos, herramientas e instituciones pertenecientes tanto al ámbito jurídico, como también educativo, médico y asistencial. ${ }^{4}$
Los procesos de "sacralización" (Zelizer, 1994) y de "estandarización" (Sommerville, 1990) de la infancia, registrados en Europa y Estados Unidos entre 1880 y 1920, impactaron fuertemente en América Latina y Chile en particular hacia la década de 1920, traduciéndose en nuevas legislaciones que apuntaban a la protección, educación o, en su defecto reeducación de los niños, niñas y adolescentes. ${ }^{5}$ La infancia comienza a ser valorizada como una etapa fundamental del desarrollo que debe ser protegida y asegurada para cada ser humano, debiendo el Estado garantizarla vigilando y fiscalizando a las familias. Con la extensión de la educación obligatoria, el establecimiento del Estado Asistencial, el desarrollo de las disciplinas psi y de la medicina social, la influencia de los programas de higiene social y mental, se fue forjando un modelo estandarizado de infancia y adolescencia que respondía, a su vez, a una visión utópica de la sociedad. Como señalara Cunningham (2005) para el caso europeo post Primera Guerra Mundial, también en Chile hacia 1920 la infancia era considerada un tema público de carácter crítico, donde ésta aparecía como la clave para construir y defender "el futuro de la nación y de la raza" (p. 191). El modelo estandarizado de infancia y adolescencia fue dibujando las fronteras de lo que era considerado "normal" y "anormal" para los niños y niñas de acuerdo a su sexo y edad y así, de acuerdo a este ideal, los niños comenzaron a ser evaluados, observados y tratados por las distintas prácticas e instituciones especializadas.

En 1920 se aprueba en Chile la Ley de Instrucción Primaria Obligatoria. En el contexto de la "cuestión social", la educación se instauró como una de las principales armas para luchar contra los problemas de higiene y las "enfermedades de trascendencia social" (como la tuberculosis, la sífilis, el alcoholismo, la prostitución, entre otras) que diezmaban a la población y amenazaban lo que en aquella época era concebido como "raza chilena". En el marco de un fuerte espíritu nacionalista que traspasaba los colores políticos (Barr-Melej, 2001), dicha ley pretendía ampliar la educación a los sectores populares. Sin embargo, sus deficiencias no tardaron en hacerse evidentes. Como señalara Rojas Flores: "En la década de 1920, diversos sectores participaron en un activo debate sobre la educación primaria y secundaria, dejando en evidencia sus limitaciones y potencialidades" (Rojas Flores, 2010, p. 327). Ya para 1924, los diagnósticos acerca de la implementación de la ley eran fatales: "se planteó que ésta había fracasado en sus propósitos, ya que ni la matrícula ni la asistencia habían crecido en forma significativa, y tampoco el número de escuelas y maestros" (Rojas Flores, 2010, p. 328). 
Aunque la ley fue aprobada en 1920, fueron necesarias diversas transformaciones a nivel cultural y social, para que las nuevas representaciones acerca de la infancia tomaran cuerpo en prácticas e instituciones específicas. A partir de 1925, con la aprobación de la nueva Constitución Política y las reformas sociales, comenzó a gestarse la modernización del Estado y la construcción de un Estado asistencial. En ese contexto, disciplinas como la medicina, la pedagogía y el trabajo social comenzaron a tener mayor presencia e injerencia pública. El foco de las políticas públicas orientadas a abordar los problemas sociales de la época, como las "enfermedades de trascendencia social", pero también la mortalidad, el abandono, el vagabundaje y la delincuencia infantil, pasaban a enfocarse en la profilaxis, la prevención y la re-educación, antes que en el castigo, el tratamiento o la curación ex post. ${ }^{6}$ Es así como hacia fines de la década, hay dos iniciativas legales que tienen gran importancia en este ámbito, y que reflejan muy claramente los cambios en las visiones y percepciones acerca de la infancia en Chile: la aprobación de la Ley de Protección de Menores y la Reforma Educacional, ambas en 1928.

La Ley de Protección de Menores, inspirada en cuerpos legales similares en países de Europa y en Estados Unidos, así como en el espíritu de la Declaración de Ginebra, de 1924,7 pretendía hacerse cargo del abandono, concebido como la causa fundamental de la delincuencia infantil. ${ }^{8}$ Por medio de esta ley, el Estado se haría cargo de aquellos niños menores de 21 años que se encontraban en lo que llamaba "situación irregular": por distintos motivos habían sido desposeídos del cuidado parental y se encontraban, por ello, en "peligro material o moral". De ese modo, la ley apuntaba no solamente a quienes habían cometido algún delito, sino también a aquellos niños cuya situación de vida los transformaba en potenciales delincuentes. En este sentido, la ley no solamente castigaba las alteraciones al orden social, sino que también las prevenía de ocurrir en el futuro, y en ese sentido tenía un doble propósito: de defensa social y de re-educación (Gajardo, 1929). Los niños ya no eran concebidos como perpetradores, sino como víctimas del medio social y familiar -lo que el Juez de Menores Samuel Gajardo denominaba "la tiranía del ambiente"- y por ende las acciones que debían implementarse a su respecto no debían orientarse a castigarlos, sino a mejorar sus condiciones de vida para que, a través de la educación, pudiera evitarse que desviaran su rumbo hacia la delincuencia.

\section{LA REFORMA EDUCACIONAL DE 1928 Y LA CREA- CIÓN DE LA ESCUELA ESPECIAL DE DESARROLLO}

En el contexto del fracaso de los objetivos de la Ley de Instrucción Primaria Obligatoria, hacia mediados de 1920 se comenzaron a introducir en Chile las tesis del movimiento pedagógico que se desarrollaba en Estados Unidos y en algunos países de Europa, denominado "Escuela Nueva" o "Escuela Activa". Estas tesis se encontrarían a la base del proyecto de reforma presentado en 1925 por algunos profesores pertenecientes a la Asociación General de Profesores (AGP) al Presidente Arturo Alessandri Palma luego del entusiasmo reformista levantado por el "Ruido de Sables" y la creación de la nueva Constitución. ${ }^{9}$ Dicho proyecto "ponía en el centro de los fundamentos de la reforma al educando, cuyas necesidades se consideraban determinantes de la estructura del sistema de educación" (Serrano, Ponce de León y Rengifo, 2012, p. 266).

La AGP estaba compuesta fundamentalmente por educadores formados en el Instituto Pedagógico, el cual tenía una reconocida y fuerte tradición germánica e impronta psicológica (Sanhueza, 2013; Alarcón, 2010). En un espíritu de modernización y fuerte positivismo científico, estas instituciones pretendían levantar la pedagogía chilena sobre bases científicas, fundamentalmente a través de la experimentación psicológica (Mann, 1936). Los educadores de la AGP, muchos de ellos comisionados por el gobierno de Chile para formarse en los centros pedagógicos donde se desarrollaban los principios de la Escuela Activa, criticaban fuertemente el sistema educativo chileno, entre otras cosas, por tender a la homogenización de los niños, sin prestar atención a las diferencias individuales. La Escuela Nueva, por el contrario, proponía una educación centrada en la personalidad y habilidades físicas e intelectuales de los niños (Salas, 1942; Reyes, 2010), en el saber-hacer y en la autonomía, implicando por ello una visión más política de la educación, como herramienta de transformación social y de profundización de la democracia.

A pesar del espíritu modernizador de 1924-1925, el proyecto de reforma impulsado por la AGP tuvo que esperar hasta el primer mandato de Ibáñez del Campo, una dictadura que se extendió entre 1927 y 1931, durante la cual paradójicamente se llevó a cabo esta reforma educacional de características sumamente revolucionarias. Como señala Reyes (2010), los fundamentos de esta reforma "iluminaron, de hecho, el proceso de renovación del sistema escolar en Chile durante las siguientes décadas" (p. 47), plasmándose en la reforma de 1928. En ella se estipulaba que 
la educación tenía por objeto favorecer el "desarrollo integral del individuo, de acuerdo con las vocaciones que manifieste, para su máxima capacidad productora intelectual y manual. Tenderá a formar, dentro de la cooperación y de la solidaridad, un conjunto social digno y capaz de un trabajo creador" (DFL № 7.500, Título I, Art. 3ㅇ, 1927). Se trata de un programa centrado en el estudiante, su vocación y potencialidades, donde su propio desarrollo se concibe como parte integral del desarrollo de la sociedad.

Se afirma, además, que "la educación se desarrollará de acuerdo con planes, programas y métodos basados en la evolución psicofisiológica del educando" (DFL № 7.500, Título I, Art. 4ㅇ, 1927). Esto es, que los programas pedagógicos se apoyaran fundamentalmente en la interrelación entre los descubrimientos y propuestas de la psicología y la biología humana, lo cual, sumado al interés por lo individual, otorga una noción universal respecto de los procesos "normales" del desarrollo infantil.

Considerando esta preocupación por las diferencias individuales y por la "evolución psicofisiológica" de los niños, la reforma distinguía y creaba diversos tipos de escuela -llamadas en los sucesivo "escuelas experimentales"-, entre las cuales estaba la escuela rural, la urbana, la granja y una "escuela hogar para niños indigentes, débiles y de inferioridad orgánica, anormales y retrasados mentales" (DFL № 7.500, Título II, Art. 17으, 1927), que sería la Escuela Especial de Desarrollo. Esta última introducía los primeros pilares de la educación diferencial en Chile (Rojas Flores, 2010) y abría también con ello un campo de trabajo para "expertos" interesados por aquellos niños cuyos procesos de desarrollo parecían desviarse de la norma esperada para su edad.

Entre las escuelas experimentales se distinguían entre las de "experimentación amplia" y las de "experimentación limitada", que debían dedicarse a la investigación pedagógica y servir como "campos de observación y medios de perfeccionamiento del profesorado en general" (DFL № 5.291, Título V, Art. 102으, 1930). Las de experimentación limitada, entre las cuales se encontraba la de Desarrollo, estaban "destinadas a poner en práctica, en las condiciones propias de nuestro país, los planes y métodos de educación que se ensayen con buen éxito en el extranjero, a fin de decidir sobre la conveniencia de incorporarlos, sea parcial o totalmente, en el sistema escolar" (DFL № 5.291, Título V, Art. 102으, 1930).

La Escuela Especial de Desarrollo, orientada a la investigación pedagógica y a la educación de los niños considerados "débiles mentales", incluyó el ensayo de formas de educación especial desarrolladas de EE.UU. fundamentalmente, en el contexto de la Escuela Nueva y de la higiene mental, tema al que nos referiremos pronto. Esta escuela fue dirigida primero por el estadounidense Lloyd N. Yepsen, del Teachers College de la Universidad de Columbia, quien fue sustituido en 1931 por el chileno formado en la Universidad de California, José Flores Muñoz y, más tarde por Juan Sandoval Carrasco, quien creó una sección "dedicada a la educación de los niños retardados mentales con sistema de internado" (Caiceo, 2009, p. 106). ${ }^{10}$

Considerando la creación de esta sección con régimen de internado, así como la primera descripción de esta Escuela Especial en la ley de 1927 como institución que debía incluir a "débiles" y "retrasados mentales", pero también "indigentes" y "anormales", podemos coincidir con la afirmación de León y Rojas (2015) de que se trataba de un organismo que "combinaba la educación, la asistencia, la prevención y el control de los menores" (p. 6). Esta Escuela intentó atacar así un problema que era no sólo de carácter educativo, sino también social y jurídico: ¿qué hacer, por un lado, con los niños que necesitan métodos e instituciones especiales de educación, y por el otro, con los delincuentes o abandonados que se encuentran en "peligro material o moral"?

\section{LA PSIQUE INFANTIL, EL MOVIMIENTO DE HIGIENE MENTAL Y LA CLÍNICA DE CONDUCTA}

En 1930, el Dr. Juan Garafulic (1955) creó en la Escuela Especial de Desarrollo una Sección de Observaciones, la cual, tomando el modelo de la Sección de Observación y Clasificación de la Casa de Menores de Santiago, estaba enfocada en diagnosticar a los niños que Ilegaban a la Escuela Especial de Desarrollo. Dicho diagnóstico tenía la finalidad de determinar si el posterior destino de estos niños sería efectivamente una institución orientada a la educación especial, o si debían ser enviados en su lugar a una institución médica dedicada al tratamiento de trastornos "psico o neuropáticos” (Garafulic y Lea-Plaza, 1936).

En 1936 se funda una nueva institución, anexa a la Escuela Especial de Desarrollo, denominada Clínica de Conducta, la cual según su director, el psiquiatra Guillermo Agüero, y el pediatra Alberto Gallinato, podía ser considerada también una "clínica de psicopatología infantil" o "sección de higiene mental infantil" (1936, p. 4). Esta clínica tenía como objetivo "servir las necesidades de las Escuelas en lo que se refiere a la existencia de niños anormales desde el punto de 
vista mental", y "el estudio y solución posible de los niños mentalmente anormales repartidos en las Escuelas Primarias" (Agüero y Gallinato, 1936, p. 3). Es decir, debía recibir a aquellos niños que habían sido enviados a la Escuela Especial de Desarrollo desde las escuelas primarias y otras instituciones vinculadas a la infancia, de los cuales se sospechara algún nivel de "anormalidad mental", para su diagnóstico más preciso, y para su tratamiento.

Dentro de su esbozo histórico de la psiquiatría chilena, Garafulic establece que el primer "servicio de neuro-psiquiatría infantil" para "alienados crónicos" en Chile fue creado por iniciativa del Dr. Hugo Lea-Plaza en la Quinta Bella, dependiente del Manicomio Nacional, en 1937 (Garafulic, 1955, p. 70), es decir, casi una década después de la puesta en funcionamiento de la Escuela Especial de Desarrollo y de la Sección de Observación de la Casa de Menores, y un año después de que se abrieran las puertas de la Clínica de Conducta. En este sentido, puede decirse que estas experiencias previas, que se desarrollaron en campos disciplinares ajenos a la medicina, como son la pedagogía y la justicia, fueron sin embargo precursoras del cuidado y la atención psiquiátrica y psicológica de la infancia en Chile, imprimiendo a la posterior emergencia de la psiquiatría y la psicología infantil, unos sellos que es necesario distinguir y analizar.

De este modo, es necesario establecer en primera instancia que en Chile la preocupación por aquello que de modo intencionalmente amplio hemos llamado la "psique infantil", se puso en juego en distintos campos, particularmente la pedagogía y la justicia, y que la emergencia de campos especializados, como la psiquiatría y la psicología, fue en parte un resultado de las tensiones y negociaciones establecidas en esos otros campos a propósito de ciertas prácticas, como fueron especialmente la medición de la inteligencia y la descripción caracterológica.

En Chile, el interés por la psique infantil apareció primero en el campo pedagógico. En 1905, el profesor Rómulo Peña Maturana fundaba el primer laboratorio de psicología experimental del país en la Escuela Normal de la ciudad de Copiapó (Abarca y Winkler, 2013; Salas, 2012; Poblete, 1980). En 1908, el profesor alemán Wilhelm Mann fundaba en Santiago el Laboratorio de Psicología Experimental del Instituto Pedagógico (éste último creado en 1889), el cual dirigió hasta 1923, siendo sucedido por Luis Alfredo Tirapegui. ${ }^{12}$ Tanto para Peña Maturana como para Mann, estos laboratorios debían servir a las necesidades de la pedagogía chilena, evaluando y estableciendo la tipología del estudiantado nacional. La psicología aparecía, así, como una herramienta pedagógica, y se desarrollaba primero con ese estatuto, lejos de ser considerada una disciplina independiente con un objeto propio.

Con esta finalidad pedagógica, Tirapegui es el primero en realizar esfuerzos sistemáticos de medición del estudiantado nacional y de estandarización de tests psicológicos en Chile. En 1925, estandarizó la escala Stanford-Binet (Tirapegui, 1925 y 1941), el cual fue aplicado a más de 1.000 niños en escuelas públicas entre 1922 y 1925 (Salas, 1942). ${ }^{13}$ En 1927 publicó la adaptación del Test de Cubos de Kohs, el cual estaba destinado a medir la inteligencia a través de la imitación y la performance visual y espacial (Tirapegui, 1941). Publicó también la adaptación de la escala Alpha de los National Intelligence Tests, creados por Robert M. Yerkes y utilizados en la armada estadounidense para medir la inteligencia, y entre 1927 y 1928 desarrolló otras dos investigaciones, una destinada a medir la inteligencia de los niños delincuentes, ${ }^{14} \mathrm{y}$ otra orientada a determinar la edad normal para los diversos cursos de la escuela primaria y del Liceo (Salas, 1942, p. 144).

Con la puesta en funcionamiento del sistema de protección de menores a partir de enero de 1929, las mediciones de la inteligencia pasaron de ser una preocupación casi exclusiva del campo educacional, a ocupar también el campo judicial. Los tests que habían sido estandarizados por Tirapegui para fines pedagógicos, fueron utilizados en el campo jurídico, con fines tanto de control social, como de re-educación. Al revisar los expedientes judiciales de los niños y jóvenes que llegaban al Tribunal Especial de Menores de Santiago entre 1929 y 1942, hemos podido identificar que muchos de ellos eran enviados a "observación" a la Casa de Menores de Santiago, donde en la ya mencionada Sección de Observación y Clasificación se les aplicaban las pruebas de inteligencia que habían sido adaptadas por Tirapegui, pero ahora con la doble finalidad de estudiar científicamente a los niños "anormales", a la vez que determinar judicialmente sus destinos. ${ }^{15}$

En efecto, la Ley de Protección de Menores respondió también en parte a un cambio que había comenzado a cimentarse en el contexto judicial, particularmente en el derecho penal, donde se había pasado desde el paradigma de la Escuela Clásica hacia el de la Escuela Positiva, teniendo como consecuencias el desarrollo de las teorías de la minoridad, de la Medicina Legal ${ }^{16}$ y la Criminología, ámbitos en los cuales el conocimiento de la psicología del delincuente, fuera adulto o infantil, era central. ${ }^{17}$ 
Siguiendo el derrotero histórico que se ha venido trazando en este artículo, puede sostenerse que la creación de la Clínica de Conducta es una muestra elocuente de esta intersección entre pedagogía, criminología y psicología infantil en el contexto ya no exclusivamente educativo, ni judicial, sino también médico. Tuvo, además, la novedad de incorporar en su arsenal teórico-metodológico al psicoanálisis, el cual si bien ya tenía cierta presencia entre pedagogos, juristas, médicos y otros intelectuales antes de 1936, aun no se plasmaba claramente como inspiración de un proyecto de intervención psicológica, menos aun de carácter estatal. La Clínica de Conducta respondía precisamente a estas características particulares: era una institución de carácter estatal que se enmarcaba en un proyecto de higiene mental infantil. ${ }^{18}$

No existen investigaciones previas en Chile sobre esta Clínica, ni tampoco han podido a la fecha encontrarse archivos que permitan su estudio desde la perspectiva de las prácticas. No obstante, sabemos que la Clínica funcionó al menos hasta 1940, fecha después de la cual ya no encontramos más bibliografía referida a ella. Además, en el artículo de Garafulic obtenemos una pista coincidente con esta fecha de desaparición: él indica que a partir de 1940 los servicios de psiquiatría infantil previamente desarrollados, como el establecido en 1937 en el Manicomio Nacional; la Sección de Observación de la Casa de Menores; la Sección de Observaciones de la Escuela Especial de Desarrollo, fueron incluidos "como servicios especializados en los hospitales Roberto del Río, Arriarán, Calvo Mackenna, en la Dirección General de Protección a la Infancia, Manicomio Nacional y Clínica Psiquiátrica Universitaria" (Garafulic, 1955, p. 70). De esta manera, podemos pensar que a partir de 1940 aquellas instituciones vinculadas a la prevención, clasificación y tratamiento de las enfermedades mentales en la infancia, incluida la Clínica de Conducta, perdieron su autonomía previa, siendo disueltas en las estructuras institucionales de los hospitales.

Es importante señalar que el nombre "Clínica de Conducta", proviene de un tipo de institución creado precisamente en el marco del movimiento de higiene mental instaurado en Estados Unidos por Clifford W. Beers (1908) a comienzos del siglo XX. Este movimiento sostenía "la idea de que la promoción del bienestar infantil podría prevenir disfunciones de la adultez" (Richardson, 1989, p. 2), es decir, que era necesario implementar programas de cuidado y de prevención de las enfermedades en las infancia, para así asegurar la existencia de adultos sanos, y, con ello, de una sociedad sana. Por ello, este movimiento combinaba la preocupación por la infancia con una "utopía tecnocientífica", es decir, la confianza en que el bienestar social -amenazado por los efectos nocivos de la industrialización- iba a ser provocado por la utilización racional y sistemática de los avances científicos y tecnológicos en el campo de los problemas sociales desde una perspectiva estatal, administrativa y orientada primariamente a la población antes que a los individuos (Grob, 1987). De este modo, educación, higiene mental y Estado establecieron una trama de intercambio interesante, que se haya a la base de programas como el implementado por la Clínica de Conducta.

Por otra parte, en Chile la higiene mental se sostenía también en discursos nacionalistas presentes en partidos políticos tanto de izquierda, como de centro y de derecha. Las enfermedades mentales, al igual que las enfermedades de trascendencia social se concebían como males fácilmente reproducibles en las generaciones descendientes de quienes se desenvuelven y viven sus vidas en condiciones de pobreza y falta de educación, y la lucha contra ellas, se entendía como una responsabilidad vinculada a la defensa de la patria y de la raza. ${ }^{19}$

La historia de la higiene mental en Chile tampoco ha sido suficientemente investigada aun. ${ }^{20}$ Por los estudios de Ana María Talak (2005) en Argentina, sabemos que en dicho país la higiene mental se desarrolló en estrecha colaboración con la psiquiatría y sus instituciones hospitalarias y universitarias, a diferencia de Estados Unidos, donde recibió sus impulsos más decisivos desde ámbitos ajenos a dicho campo disciplinar, como el derecho, la pedagogía y la política (Grob, 1987). Como destaca Talak, en Argentina, donde se fundó una Liga de Higiene Mental en 1929, ésta se desarrolló en estrecha relación con la eugenesia, dando forma a la entonces llamada "medicina social", y también en relación con el emergente saber psicológico. Hasta donde hemos podido indagar, en Chile la higiene mental siguió trayectorias similares a Argentina. En 1931 se fundó en Santiago la Liga de Higiene Mental, ${ }^{21}$ cuyo principal objetivo era prevenir las enfermedades mentales, poniendo su acento en la cuestión de la heredabilidad de los caracteres adquiridos y la degeneración, es decir, en la posibilidad de que un ambiente defectuoso termine reproduciendo en los descendientes aberraciones o taras consideradas signos de enfermedad mental (Arce Molina, 1937). De ese modo, entremezclaba la preocupación por la herencia con aquella por el ambiente, y por ese motivo parte importante de sus intereses estuvieron 
enfocados en la infancia, en el emergente saber psicológico y en formas de "eugenesia negativa". ${ }^{22}$ Médicos psiquiatras, además de pediatras y de aquellos que se desempeñaban en la salubridad pública, como Lea-Plaza, Garafulic, Germán Greve, ${ }^{23}$ Luis Cubillos, el futuro presidente Salvador Allende, y muchos otros, algunos de los cuales se vincularon además a algunas de las primeras apropiaciones psiquiátricas del psicoanálisis en Chile, fueron los principales impulsores de la higiene mental en el país.

En su tesis titulada Higiene mental y delincuencia, Allende (1933) sostuvo que la higiene mental tenía como objetivos la "prevención, curación y vigilancia profiláctica de los individuos que por sus alteraciones neuro y psicopáticas constituyen una entidad desarmónica en nuestro medio social" (Allende, 1933, p. 14). Por ello, añade, la higiene mental se preocupa tanto de la protección del individuo enfermo como de la sociedad, y abarca un "vasto programa de acción médico-psicológico-pedagógico-social, cuya característica esencial es el criterio preventivo" (Allende, 1933, p. 14). Allende señala también que la higiene mental tendría las siguientes funciones de ayudarlo a "desarrollar y fortalecer su capacidad de adaptación social", "solucionar sus conflictos psíquicos", prevenir "trastornos psiquiátricos" o "evitar su repetición si éstos se han producido" (Allende, 1933, p. 14).

Como se advierte, la higiene mental incluye la preocupación por el individuo y la sociedad; la contribución de distintas disciplinas como la pedagogía, la medicina, el trabajo social y la psicología; la influencia no excluyente de perspectivas heredo-degeneracionistas y ambientalistas; y funciones no sólo de prevención, sino también de tratamiento. Podemos agregar, siguiendo a Agüero y a Gallinato, que "la higiene mental (...) que atiende a la conservación de la integridad psíquica de un individuo o de una colectividad es una función eminentemente estatal" (Agüero y Gallinato, 1937, p. s/n), es decir, es concebida como un deber del Estado, una función pública, y no una preocupación privada.

De acuerdo a lo señalado por una de las visitadoras sociales de la Clínica de Conducta, Christine Galitzi, ${ }^{24}$ su meta principal es "descubrir desde la más tierna infancia las reacciones mentales y emotivas defectuosas de los niños, que podrían degenerar, si no se las trata, en hábitos viciosos perjudiciales para la salud del adulto" (Galitzi, 1937, p. 613)..$^{25}$ Esta distinción entre lo mental y lo emotivo, que retoma la realizada por Allende entre los "trastornos psiquiátricos" y los "conflictos psíquicos", es fundamental, como veremos en lo que sigue, para el enfoque adoptado en la Clínica de Conducta con apoyo en el psicoanálisis, donde lo "afectivo" o "emocional" (términos que se ocupan indistintamente) pasa a primer plano.

\section{EL TRABAJO DE LA CLÍNICA DE CONDUCTA: HIGIENE MENTAL Y PSICOANÁLISIS}

Combinando las ideas del movimiento estadounidense de higiene mental con las de psicoanalistas europeos como Sigmund y Anna Freud, Alfred Adler, Ernest Jones, Marie Bonaparte y Charles Baudouin, la Clínica de Conducta promovió un sistema de atención basado en la "observación de la vida emocional o afectiva" (Agüero y Gallinato, 1936, p. 6) en los primeros años de vida de los niños. Su finalidad era prevenir la instalación de ciertos patrones de "conducta antisocial" o modificarlos en este momento de mayor flexibilidad, en el caso en que ya se hayan fijado. En este doble sentido, los "procedimientos que hemos usado para prevenir futuras desadaptaciones", señala Agüero, "son la acción profiláctica y terapéutica" (Agüero, 1938, p. 31), es decir, prevenir si aun es posible, corregir cuando ya es demasiado tarde.

Para Agüero y Gallinato, los “síntomas de desadaptación" que pueden observarse en los niños que son enviados a la Clínica, pueden ser entendidos como manifestaciones de "afectividad no liberada", la cual se encuentra en estado de "inhibición o represión emocional" (Agüero y Gallinato, 1936, p. 6). Explican que "la energía instintiva al disociarse y reagrupares forma un mosaico intermedio que son precisamente los complejos que en el adulto se halla en las substructuras y en el niño en un primer plano" (Agüero y Gallinato, 1936, p. 6). Entendidos como "detenciones del desarrollo" (p. 6), se encuentran entre los procesos afectivos (y el instinto) y los procesos psíquicos superiores, y pueden ser abordados no sólo desde la psicoterapia, sino también desde la higiene mental.

A la base de las "manifestaciones antisociales objetivas" se encontrarían los "conflictos de carácter afectivo, afectivo-moral o simplemente intelectual" ((Agüero y Gallinato, 1937, p. s/n), provocados la mayor parte del tiempo por las privaciones de índole socioeconómico que no permiten un normal desenvolvimiento y desarrollo de los niños, es decir que serían dichas privaciones las que en última instancia provocarían la detención del desarrollo:

Es sabido que una parte de las psiconeurosis aparecen como resultado de un conflicto del individuo con el medio, conflicto que, en muchos casos, significa una inseguridad del sujeto para la satisfacción de 
sus necesidades nutritivas. De aquí se desprende que todos aquellos mecanismos que tiendan a asegurar al individuo estas necesidades primordiales -en otras palabras, su futuro equilibrio económico- contribuirán a disminuir las posibilidades de la aparición de fenómenos de carácter neurótico, efectuando también, de este modo, una labor de higiene mental (Agüero y Gallinato, 1937, p. s/n).

En este sentido, vemos que se trata de niños provenientes de las capas más pobres de la población, donde las condiciones sociales de vida tienen gran injerencia en su desarrollo y permiten explicar la prevalencia de trastornos mentales.

Según se desprende de la cita anterior, Agüero y GaIlinato utilizan la teoría energética elaborada por Sigmund Freud y Joseph Breuer en Estudios sobre la histeria (Freud y Breuer, 1998), con la finalidad de explicar las conductas antisociales de los niños: la energía no liberada vinculada a la satisfacciones de las necesidades primordiales, como es la nutrición, puede ser retenida y aplicada a diversos fines que entran en contradicción y conflicto con las normativas sociales. Para los médicos de la Clínica, el conflicto no es intrapsíquico sino producido por un choque entre las energías psíquicas y las condiciones sociales. De este modo, la labor de la Clínica no es sólo atacar los síntomas psicológicos, sino al mismo tiempo su ambiente familiar y social. Estos dos niveles son planteados como la necesidad, por una parte, de "solución de estos conflictos primitivos (Procedimiento Psicogenético)" y, por la otra, de "crear hábitos sociales en el sujeto (Procedimiento Behaviorístico o Reflexológico)" (Agüero y Gallinato, 1937, p. s/n), es decir, una mezcla entre lo "psicogenético" -otro nombre para el psicoanálisis-y un conductismo interesado en el modelamiento y la transformación de hábitos antisociales en sociales.

Los autores, que indican no querer abanderarse con una u otra escuela de pensamiento, sino hacer uso de aquello que sirva para sus fines, encuentran principalmente en los planteamientos de Freud, Adler y Karl Marx, las bases precisas para trabajar los problemas que se les presentan. ${ }^{26}$ Señalan que "los niños son estudiados desde el mismo cuádruple aspecto indicado por Allende en 1933, el cual abarcaría todas sus manifestaciones: aspecto social, médico, pedagógico y psicológico", y que "luego se llega a un diagnóstico de su alteración y en seguida se procede a su tratamiento, aprovechando todo aquello que nos brindan las circunstancias" (Agüero y Gallinato, 1937, p. s/n).

Sostienen que "es necesario aprovechar los numerosos hallazgos de las Escuelas Psicogenéticas de
Freud y sus continuadores y no detenerse en la Psicología Clásica o Constitucional, la cual se ha manifestado estéril para resolver numerosos conflictos" (Agüero y Gallinato, 1936, p. 6). El psicoanálisis aparece así como un cuerpo teórico crítico a la psicología experimental, que permite abordar aspectos que ésta no lograba resolver.

Dentro de los métodos y técnicas utilizados para 1938 en la Clínica de Conducta, Agüero nombra: la escala Binet-Simon, herramienta frecuente de las evaluaciones psicológicas de la época; los métodos propios del psicoanálisis infantil, como son "la interpretación psicoanalítica de los dibujos y creaciones infantiles", que permiten "profundizar en los móviles y determinantes inconscientes de su conducta" y "la interpretación de los juegos, sueños y creaciones imaginativas de los niños"27; "las pruebas psicoanalíticas clásicas -asociaciones libres y determinadas-" (Agüero, 1938, p. 34); y en último lugar se reconoce que "en otros casos será conveniente aprovecharse de los datos de la Psicología Individual de Adler y estimular en el niño el sentimiento de comunidad" (Agüero y Gallinato, 1936, p. 6).

Estos métodos -exceptuando la escala Binet-Simon- eran utilizados entonces para estudiar los "conflictos de los niños con sus padres y con sus hermanos, los complejos de destrucción y de exhibición o narcisista (...) los complejos de mutilación y de misterio o Enigma de la Esfinge en que el niño se pregunta como llegó al mundo. (...) los llamados complejos de actitud de los cuales los principales son el destete y la retirada" (Agüero y Gallinato, 1936, p. 6). ${ }^{28}$

La Clínica buscaba entonces, a través del estudio de los conflictos afectivos y de un trabajo psicoterapéutico y profiláctico, provocar la liberación de las energías afectivas reprimidas o inhibidas que estaban produciendo los conflictos, para entonces redirigirlas hacia metas más elevadas y socialmente aceptadas, es decir, hacia la "sublimación". En el medio en que estos niños se desenvuelven, señalan Agüero y Gallinato, "un ambiente pobre, estrecho e hipócrita cuando no hostil" (Agüero y Gallinato, 1936, p. 6), su vida afectiva no es en absoluto considerada, y por lo tanto no existe el espacio tampoco para asegurar la adecuada expresión y liberación de dichas energías. Para ello, los autores consideran que las nuevas orientaciones pedagógicas provenientes de la Escuela Nueva, que estaba a la base de las reformas educacionales que llevaron a la creación de la Escuela Especial de Desarrollo, convergen con el proceso psicoanalítico y pueden colaborar en ese proceso de tratamiento psíquico y de higiene mental. Cito in extenso: 
Precisamente uno de los principales objetivos de las nuevas escuelas y nuevas tendencias educacionales es facilitar el libre desenvolvimiento de las actividades emocionales infantiles a fin de que el niño llegue a la vida del trabajo por un bagaje de confianza en sí mismo, iniciativa y creación.

En estas nuevas orientaciones habrá que tomar muy en cuenta el simbolismo de sus sueños, de sus juegos, de sus fantasías, de sus creaciones y de su conducta y el mecanismo de desplazamiento afectivo, base del símbolo, que nos abre camino al proceso Psicoanalítico más interesante o sea la sublimación, la utilización de las energías afectivas en procesos más altos, desde el punto de vista de la utilidad social. Recordaremos a este propósito que la vía de orientación hacia la formación de los mecanismos sublimatorios es la formación de una consciencia, moral, el super-yo, la cual reside en una identificación del niño con sus padres y educadores (Agüero y Gallinato, 1936, p. 6-7).

De este modo, el desarrollo del niño en un ambiente favorable que le permita desenvolverse libremente y el desarrollo de "una aptitud vocacional" antes desconocida, tiene como efecto liberar las energías fijadas en determinados complejos infantiles, para redirigirlas desde las actividades antisociales en las que se manifestaba, hacia "tendencias creadoras y constructivas" (Agüero, 1938, p. 36).

No es extraño que la lucha contra las enfermedades mentales y contra las conductas antisociales en el contexto de la defensa de la patria y de la raza, tome de los arsenales del psicoanálisis a la sublimación como una importante herramienta. El uso del concepto de sublimación en distintos campos de apropiación del psicoanálisis en Chile ya ha sido destacado en la historiografía reciente (Ruperthuz, 2016; Ruperthuz y Vetö, 2016), y ha sido explicado principalmente desde las posibilidades que ofrece en cuanto a la modificación y el modelamiento de las "pulsiones" sexuales y agresivas ${ }^{29}$ en favor de programas de utopía social. Como señala el Juez de Menores Samuel Gajardo a propósito de la educación sexual, se trata de "la disciplina de los instintos y la canalización de las tendencias biológicas, que no es posible extirpar, pero tampoco eximir de control. (...) Ello ofrece un hermoso programa cultural, de utilización de nuestras tendencias egoístas en beneficio de los intereses humanos" (Gajardo, 1940, p. 200).

En 1938, Agüero y el Dr. Luis Cubillos, publican un texto titulado "Consideraciones sobre Clínicas de Higiene Mental Infantil y delincuencia de menores", donde encontramos un mayor espesor teórico en lo referente al psicoanálisis y a sus nexos con la crimi- nología, campo específico en que se desempeñaba Cubillos. ${ }^{30}$ Como ambos psiquiatras exponen, el uso que hacen del psicoanálisis en la Clínica no se refiere al tratamiento propiamente tal, sino a su valor como criterio de observación y diagnóstico:

A propósito del psicoanálisis como procedimiento terapéutico debemos declarar que en la Clínica Psiquiátrica Infantil es, según nuestra experiencia, de limitados resultados, sobre todo cuando se trabaja con un número crecido de niños, como en nuestra Clínica, pero es de enormes alcances, y a nuestro juicio, imprescindible como criterio etiológico y patogénico para alcanzar el núcleo central de las manifestaciones anormales y fundar la profilaxis o terapéutica. En ese núcleo es esto de tanta importancia que estimamos que la abstención del criterio analítico en una Clínica de Conducta esterilizaría su acción (Agüero y Cubillos, 1938, p. 34).

El "criterio psicoanalítico" lo definen como "la interpretación de la conducta y de los actos simbólicos como resultado de tendencias y afectos más o menos inconscientes y determinados por los sucesivos estados de la evolución instintiva, tanto sexual como trófica y agresiva" (Agüero y Cubillos, 1938, p. 45-46).

En su escrito, que trata específicamente de la delincuencia de menores, Agüero y Cubillos ponen especial énfasis en las tendencias agresivas, argumentando desde "El malestar en la cultura" (Freud, 1998b) que "los hombres modernos sufren probablemente más por la represión de sus instintos agresivos que por la de sus instintos sexuales" (Agüero y Cubillos, 1938, p. 47). Agregan que las tendencias agresivas "ocultan en el fondo una destrucción que, en muchos casos, obedece a la necesidad de nutrirse y asegurarse el porvenir" (Agüero y Cubillos, 1938, p. 47). Por ello, concluyen, "no nos ha de extrañar encontrar un tan alto porcentaje de déficit económico en los desadaptados, los cuales se encuentran, precisamente, en una gran proporción fijados en la etapa destructiva o sádicoanal de su vida instintiva" (Agüero y Cubillos, 1938, p. 47). Así, la delincuencia puede ser explicada desde la referencia a fijaciones en estadios del desarrollo psicosexual y a motivaciones inconscientes, sin dejar de lado la influencia del medio social y familiar. En última instancia, para los autores lo que se encuentra a la base de los trastornos inconscientes que motivan la delincuencia es el déficit económico, y por ende lo que el servicio del higiene mental debe hacer es, antes que nada, un trabajo de carácter social.

Para diciembre de 1936, tras tres meses de funcionamiento, la Clínica había recibido un total de 57 ni- 
ños, 42 hombres y 15 mujeres. De acuerdo a Agüero, la gran mayoría de ellos eran "niños proletarios, de la clase media, y especialmente de la clase baja, como son en general los niños de nuestras escuelas primarias" (Agüero y Cubillos, 1938, p. 31), es decir, niños en quienes pueden descubrirse aquellas carencias económicas ya mencionadas.

Para comienzos de 1938, Agüero señala haber "inscrito y estudiado 130 niños de ambos sexos, entre 4 y 18 años, preescolares, escolares y postescolares", de los cuales 35 no pudieron ser atendidos, en muchos casos por "falta de cooperación familiar" (Agüero y Cubillos, 1938, p. 32). De los restantes 95 niños en tratamiento, 65 serían hombres y 30 mujeres, los cuales son ubicados en un extraño sistema clasificatorio que mezcla categorías descriptivas con analíticas, categorías orgánicas con psicológicas y psicoanalíticas:

a) "oligofrenia (débiles mentales y morones)";

b) "trastornos conductuales secundarios al pauperismo";

c) "traumatismos cráneo-cerebrales graves";

d) "desnutrición y raquitismo";

e) "otros trastornos orgánicos";

f) "accesos convulsivos";

g) "disendocrinias";

h) "heredo-lúes";

i) "encefalopatías";

j) "trastornos del lenguaje".

k) “¿perversión instintiva?”;

l) "trastornos por conflictos familiares";

m) "insuficiente formación del yo-moral";

n) "trastornos por exceso de mimo";

o) "sentimientos de inferioridad";

p) "fijación edipiana";

q) "rivalidad fraternal";

r) "introversión y narcisismo"; "

s) "enuresis";

t) "timidez";

u) "onanismo";

v) "fijación afectiva infantil";

w) "mala inducción del ambiente";

x) "trastornos producidos por el cine";

y) "en observación"; y

z) "sin trastornos" (Agüero, 1938, p. 32).

Como puede advertirse, entre estos 153 casos, encontramos todo tipo de diagnósticos, desde "debilidad mental", hasta "trastornos producidos por el cine", desde "disendocrinias" hasta "fijación edipiana". Se trata de una variedad de casos entre los cuales hay causas orgánicas y ambientales, los cuales comparten, sin embargo, que "dificultan la adaptación del niño al medio escolar y social, produciendo una perturbación en dichos medios, al mismo tiempo que impiden el desarrollo normal de ese niño, el que, pasando el tiempo, queda colocado al margen de la colectividad" (Agüero, 1938, p. 31). ${ }^{31}$

De estos 153 casos, 31 fueron diagnosticados como "oligofrénicos", es decir, con algún nivel de "debilidad mental". Sabemos que la debilidad mental era establecida fundamentalmente a través de la aplicación de la escala Binet-Simon, contrastada a veces con el Test de Cubos de Kohs y por la observación clínica. Se concebía que la debilidad mental pudiera ser causa de trastornos conductuales, por lo cual era de suma importancia un diagnóstico preciso. ${ }^{32}$

Sin embargo, Agüero señala también que "gran parte de aquellos niños que constituyen problemas escolares, familiares y sociales presentan una inteligencia por lo menos normal, residiendo entonces el núcleo de su trastorno en una alteración orgánica y principalmente afectiva como luego veremos" (Agüero, 1938, p. 32). Es decir, los trastornos de la inteligencia se distinguen de aquellos que provienen de una causa orgánica, y también de aquellos que tienen una causa afectiva, esta última tan importante en los casos tratados en la Clínica. El "pauperismo -agrega- actúa por un doble mecanismo, a la vez orgánico (desnutrición) y afectivo (sentimiento de injusticia e incompletud)" (Agüero, 1938, p. 32), es decir, que el déficit económico es causa tanto orgánica como afectiva de todo tipo de trastornos conductuales infantiles.

Siguiendo con los "factores afectivos de desadaptación", se sostiene que constituyen más de la mitad de los casos, y que "ellos van consignados en los trastornos por el pauperismo, por conflictos familiares, por insuficiente formación del yo-moral o introyección defectuosa de los reglamentos y normas éticas personificados en la autoridad del padre, en los trastornos por exceso de mimo (...), "en las alteraciones derivadas de los sentimientos o complejos de inferioridad, en las fijaciones afectivas infantiles, relativamente frecuentes..." (Agüero, 1938, p. 32-33).

Ahora bien, respecto del trabajo efectuado con estos niños, si bien se establece que en la mayor parte de los casos (23 de 110) la "acción de la Clínica [fue] dificultada por diversos motivos", en aquellos en que 
sí se pudo llevar a cabo alguna acción, los métodos más utilizados fueron los siguientes: "Acción psicoterápica directa"; "Modificación de la conducta de los familiares hacia el niño"; "Tratamiento médico"; "Colocación en establecimientos apropiados (Escuela Especial de Desarrollo, Settlement Municipal, etc.)" (Agüero, 1938, p. 33). ${ }^{33}$

Enfocándonos exclusivamente en la "acción psicoterápica directa”, veremos que esta refiere, "por una parte, aquella que se deduce de la modificación que experimenta la personalidad del niño al saberse y sentirse objeto de un interés especial por parte del psicólogo, y por otra, las modificaciones, generalmente lentas, que se van produciendo en su carácter y en su conducta por acción de las sugestiones de aquél" (Agüero, 1938, p. 33). Siguiendo el modelo de la psiquiatría de fines del siglo XIX y comienzos del XX, tradición en la cual en un principio se incluye también Freud (Shamdasani, 2005), la psicoterapia tenía relación directa con la sugestión, es decir, con la influencia que podía tener sobre el niño la personalidad del médico. Así, el primer y principal desafío del médico, consiste en alejarse de la identificación con un "juez o censor" que pretendería examinarlo, estudiarlo o evaluarlo moralmente: "símbolos sádicos de autoridad y castigo, a veces peligro de mutilación" (Agüero, 1938, p. 33). Frente a ello, explica Agüero, el niño reacciona "replegándose mentalmente sobre sí mismo (reacción instintiva de miedo) y generándose en él una especie de introversión o tratando de engañar al médico, reprimiendo por un proceso de defensa, consciente o inconsciente, sus vivencias o deseos" (Agüero, 1938, p. 33-34), impidiendo u obstaculizando el estudio de su personalidad y su conducta. Como vemos, la situación psicoterapéutica, se entiende siguiendo no sólo los postulados de la psiquiatría decimonónica, sino también del psicoanálisis, donde el médico puede ser objeto de una "transferencia" que genere una reacción negativa al proceso terapéutico. ${ }^{34}$

A pesar de estas referencias, cuando Agüero explica la finalidad de la acción psicoterapéutica, se aleja bastante del psicoanálisis, reclamando un lugar para los procesos de modelamiento de la conducta con fines de adaptación: "Volviendo a la acción psicoterapéutica creemos que su fin debe [ser] adaptar al niño a sus problemas o habituarlo a tener otros problemas, y sólo en determinadas ocasiones pretenderá curar o mejorar..." (Agüero, 1938, p. 34). Y luego agrega: "Su objeto es destruir malos hábitos derivados de la educación anterior, cambiándolos por hábitos nuevos más adaptados a la realidad y a la sociabilidad" (Agüero, 1938, p. 34).

\section{A MODO DE CONCLUSIÓN}

El caso de la Clínica de Conducta puede iluminar formas tempranas de acercamiento a la psique infantil en Chile, permitiendo así historizar algunas áreas de los saberes psi que aun no han sido explorados suficientemente por la literatura especializada. En particular, esta Clínica permite indagar los nexos establecidos entre higiene mental infantil, en tanto programa estatal, con el psicoanálisis, y, de ese modo develar no sólo los campos de apropiación de ambos saberes en Chile, sino también las peculiaridades de sus desarrollo e hibridaciones.

Respecto de dichos campos de apropiación, permite advertir cómo los saberes psi comenzaron a ser recibidos y transformados para dar respuestas a problemáticas sociales sumamente relevantes, como la educación, el abandono y la delincuencia infantil. En ese sentido, permite también mostrar cómo estos saberes se fueron desarrollando en tensiones, negociaciones y solidaridades con otras disciplinas, como la pedagogía, la medicina, el derecho, y la criminología.

En ese contexto, el psicoanálisis parece haber sido utilizado de manera ecléctica, poco ortodoxa y no institucionalizada, es decir, como un discurso entre otros disponibles, que podía ser leído, moldeado e interpretado en función no de propósitos gremiales, sino de sus fines de intervención social. El psicoanálisis confluye allí con la pedagogía, la higiene mental y la criminología, logrando una adaptación fértil e interesante que aproximadamente una década más tarde, cuando comienza a institucionalizarse, comenzará a ser obliterada en provecho de los intereses de un gremio en formación.

En la Clínica de Conducta, donde la higiene mental confluye con el psicoanálisis, se ponen en juego dos tipos de intervenciones que aparecen claramente en los textos analizados: de un lado la profilaxis, las intervenciones sociales y la modificación de conducta, basada en el Behaviourismo, y de otro lado la posibilidad de una psicoterapia sostenida en el psicoanálisis. Este último tiene un lugar también en un proceso previo al diseño de las intervenciones o planes de trabajo: la observación, la identificación y el diagnóstico, donde además de los tests que permiten evaluar la inteligencia, encontramos la interpretación del juego, del dibujo y de las asociaciones de los niños, los cuales permiten analizar los conflictos afectivos y los complejos. Sin embargo, otra particularidad que proviene de la hibridación entre psicoanálisis e higiene mental, de la puesta en conjunto de un interés por la sociedad y por el bienestar individual, es que los conflictos psíquicos no se conciben como algo remitido 
exclusivamente a lo privado, a la historia individual, tampoco meramente a la historia familiar. Los conflictos son siempre producidos por el encuentro con las condiciones materiales de vida, las cuales permiten $u$ obstaculizan la libre expresión de los afectos y, de ese modo, determinan su encauzamiento por vías sociales o antisociales. Es por ello que, a pesar de lo que pueda parecer a primera vista, el paradigma de enfermedad mental que se halla a la base de la experiencia de esta Clínica no es puramente orgánico y hereditario, sino que concibe la articulación entre dichos aspectos de la vida humana, con las condiciones sociales.

En tal sentido, y volviendo a las utopías sociales propias de los programas higienistas, cabe afirmar que el psicoanálisis, por medio de la psicoterapia y sobre todo del uso de la sublimación, fue pensando en la Clínica de Conducta como una herramienta que podría servir para la adaptación de los niños: pasar de lo antisocial a lo social, de los malos hábitos y los vicios a una vida

\section{NOTAS}

1. A riesgo de anacronismo, conscientes de que la noción de "salud mental" responde a una ideología del bienestar más contemporánea, en esta primera aproximación lo utilizaremos genéricamente para referirnos a la historia de la psiquiatría, neuropsiquiatría, psicología e higiene mental infantil chilena.

2. Con esto nos referimos a las denuncias vinculadas a los centros del Servicio Nacional de Menores (SENAME), en los cuales se han producido en los últimos años un gran número de muertes de niños que se encontraban allí para ser protegidos por el Estado, sin hablar de las negligencias y efecto iatrogénico producidos en dichas instituciones. Hacemos referencia también a las deficientes redes públicas de atención médica infantil, ya sea mental o de otro tipo, así como a la delincuencia infantil y adolescente, respecto de la cual las formas de abordaje implementadas por el Estado parecen no aportar solución efectiva.

3. Otras investigaciones ya han documentado procesos de recepción y apropiación del psicoanálisis donde éste es dinámicamente entremezclado con aspectos de higiene social y mental, medicina social y otros saberes y prácticas afines. Véase, entre otros: Ruperthuz (2016); Gallo (2013); Zaretsky (2012); Plotkin (2003); Vezzetti (1996a y 1996b); Damousi (2005).

4. Para los procesos europeos y estadounidenses, véanse, entre otros: Chávez-García (2016); Platt (2009); Pierre (2008); Vigarello (2005); Tanenhaus (2004); Hendrick (1997 y 2005); Cunningham (2005)

5. Para el caso argentino, véase el trabajo de Stagno (2011)

6. Véase: Illanes (2007 y 2010); Zárate (2008). socialmente útil y ejemplar. Los niños son un aspecto clave en este proceso de transformación tecno-utópica donde la ciencia parece tener tanto que decir: son el futuro de la nación, de la raza, de la patria, y en ese sentido son la arcilla de la cual los expertos -médicos, psicólogos, pedagogos, juristas, visitadoras socialespodrían hacer desaparecer los comportamientos y los hábitos potencialmente destructores del ideal social, para moldear en ellos las conductas con las cuales construir una ahora depurada sociedad.

\section{AGRADECIMIENTOS}

Este artículo se inscribe en el marco de dos proyectos de investigación, un Fondecyt de Iniciación $\mathrm{N}^{\circ}$ 11160868 (2016-2019), titulado "Niños vulnerables, niños peligrosos: construcción de la infancia en los archivos del Tribunal Especial de Menores de Santiago, 1928-1942", y en un proyecto Jorge Millas/UNAB, DI1215-16/JM (2016-2017).

7. El 24 de septiembre de 1924 la Sociedad de Naciones aprobó la Declaración de los Derechos del Niño, un texto breve y general que planteaba, entre otras cosas, que "el niño debe ser puesto en condiciones de desarrollarse normalmente desde el punto de vista material y espiritual", que deben ser alimentados, cuidados, protegidos, socorridos, y que los niños delincuentes o "desadaptados deben ser re-educados". Ese mismo año, en el Congreso Panamericano del Niño celebrado en Santiago (Rojas Flores, 2010, p. 360), Chile se hizo parte de la declaración y adhirió asimismo a la Oficina Internacional de Protección a la Infancia, con sede en Bruselas. La Declaración de Ginebra está disponible en: http:// xn--derechosdelnio-2nb.com/declaracion-de-ginebra.html

8. Acerca del abandono infantil en Chile, véase el trabajo de Nara B. Milanich en general, y en particular su libro Children of Fate (Milanich, 2009).

9. En septiembre de 1924, habiendo el Parlamento desestimado la aprobación de trascendentales reformas sociales, se preparaba a aprobar un aumento en su dieta parlamentaria. Frente a esta situación, un grupo de militares, entre los cuales se encontraba el futuro Presidente Carlos Ibáñez del Campo, se instalan en el Congreso y hacen sonar sus sables contra el mármol del Salón, en clara señal de reprobación y amenaza. Dicho episodio fue conocido como "Ruido de Sables". Así conminados, los parlamentarios aprobaron apresuradamente las reformas sociales, iniciando el proceso que culminaría con el fin del parlamentarismo oligárquico y la redacción de una nueva Constitución Política, en 1925, una vez que Alessandri retornara del extranjero, donde se refugió durante los meses en que un Comité Militar tomó el control del país y del congreso. 
10. En términos de investigación pedagógica, una de las principales iniciativas de experimentación realizadas en la institución fue la estandarización del test Myers-Briggs, una prueba de personalidad basada en los "tipos psicológicos" de Carl Gustav Jung, la cual fue realizada a más de 15.000 alumnos de escuelas primarias de Chile entre 1929 y 1932, obteniendo normas por cursos y edades (Salas, 1942, p. 115-116). Sobre la prueba, véase: Flores Muñoz (1932). Véase también: Yepsen (1930); Sandoval Carrasco (1941).

11. Muchos de los niños que llegaban a la Escuela Especial de Desarrollo, eran enviados allí por el Juez de Menores Samuel Gajardo Contreras desde el Tribunal Especial de Menores de Santiago, creado a partir de la aprobación de la Ley de Protección de Menores en octubre de 1928, y que entró en vigor el 1 o de enero de 1929. Dicha Ley había puesto en funcionamiento una serie de instituciones: además del Tribunal, la Dirección General de Protección de Menores, la Casa de Menores de Santiago y el Politécnico de Menores Alcibíades Vicencio. Todo este dispositivo apuntaba a menores de 20 años que habían delinquido o que se encontraban en lo que en la época se denominaba "situación irregular", es decir aquellos cuya situación familiar se presumía podía potencialmente empujarlos a la delincuencia. Muchos de los niños que llegaban al Tribunal eran enviados a evaluación por expertos (médicos, psicólogos, pedagogos y visitadoras sociales) en la Sección de Observación y Clasificación de la Casa de Menores de Santiago. Allí se les realizaban diversas pruebas y evaluaciones, entre ellas los tests de inteligencia, aplicados por el psicólogo de la institución, Abelardo Iturriaga Jamett. Aquellos que tras la evaluación eran diagnosticados con retraso intelectual grave, como "debilidad mental profunda", "imbecilidad" o "idiocia”, eran enviados a la Escuela Especial de Desarrollo a proseguir allí su educación. Véase: Lea-Plaza (1929 y 1934); Iturriaga (1929, 1930 y 1935).

12.Sobre historia de la psicología en Chile, véase: Laborda y Quezada (2010); Salas y Lizama (2009); Winkler (2007).

13. Esta escala es la adaptación de la escala Binet-Simon (19041911) realizada por Lewis M. Terman en Stanford University en EE.UU. en 1916.

14.Si bien no tenemos información respecto de qué tests se utilizaron para ese fin, podemos hipotetizar que se trató del test de dibujo de Healy, el cual sabemos por otras fuentes que se ocupaba profusamente para esos fines en esa época en Chile.

15. Un sinnúmero de publicaciones de la época dan cuenta de este interés por la medición de la inteligencia de los niños en el contexto judicial. Véase, entre otros: Gallinato (1941); Iturriaga (1929, 1930 y 1935); Lea-Plaza (1934).

16. Que aunque ya se venía desarrollando en el campo médico desde fines del siglo XIX, recién en esta época comienza su crecimiento en el campo del derecho.

17.Para ampliar este aspecto referido al cambio de la Escuela Clásica a la Escuela Positiva en Chile, véase: Carnevali
(2008); Matus (2010); León (2012). Para revisar el desarrollo de la criminología en Chile, particularmente a partir de las publicaciones de la Revista de Ciencias Penales, véase Carnevali y Matus (2007). Para profundizar en las transformaciones jurídicas acerca del estatuto de los niños en Chile, véase: Cillero (1994 y 2001); Couso (2000); Toledo y Zúñiga (1991)

18. Para la historia temprana del psicoanálisis en Chile, véase: Vetö y Sánchez (2017); Ruperthuz (2016); Vetö (2016); Ruperthuz y Vetö (2016).

19. En su tesis de Doctorado, Claudia Araya Ibacache (2015) traza una interesante relación entre la perspectiva heredo-degeneracionista y la influencia de la higiene mental en Chile. De forma sumaria, podemos decir que ella demuestra que la idea de que la enfermedad mental no podía ser curada $a$ posteriori, implicó que los médicos orientaran sus esfuerzos a la prevención de las mismas, lo cual se encontraba a la base del movimiento de higiene mental.

20. Aquí sólo pretendemos sentar algunos antecedentes para otras investigaciones que, tomando tal vez la inspiración del estudio de caso y su contextualización (Mülberger, 2014), superen la sola experiencia de la Clínica de Conducta. Además de los aportes ya mencionados de Araya Ibacache en el contexto de los procesos de profesionalización de la psiquiatría en Chile, desde hace algún tiempo Mariano Ruperthuz investiga esta temática en el marco de su tesis de Doctorado en Historia en la Universidad de Santiago. Si bien aun no hay publicaciones al respecto, podemos referir a su exposición realizada en febrero de 2017 en el Departamento de Historia de la Ciencia del Instituto de Historia, CCHS-CSIC, en Madrid, titulada "Combatir las enfermedades a causa del maquinismo. La Asociación Chilena de Higiene Mental y un nuevo régimen de temporalidad en Chile (1925-1930)".

21. Cabe destacar que hay alguna incertidumbre respecto del nombre de esta institución, ya que a pesar de que en las fuentes por mi revisadas se habla de una "Liga de Higiene Mental" fundada en 1931, Mariano Ruperthuz me ha indicado que hay otros que hablan de una "Asociación Chilena de Higiene Mental", fundada en 1932. No hay claridad aun si se trata de la misma institución, primero fundada como Liga y que al año siguiente hubiera modificado su nombre a Asociación, si se trata de dos instituciones distintas (opción bastante improbable), o bien de una confusión de nombres y fechas en los textos revisados. De todos modos, en la Biblioteca Nacional de Chile se pueden hallar las Bases generales y proyecto de programa de la Asociación Chilena de Higiene Mental, publicada en Santiago por la Imprenta Universo en 1932. Sea como fuere, gracias a Garafulic (1955) sabemos que se disolvió en 1949 tras la muerte del Dr. Arturo Vivado, quien por entonces era el profesor titular de la Cátedra de Psiquiatría de la Universidad de Chile.

22. Para abordar de manera más específica las relaciones entre el psicoanálisis, el higienismo y la eugenesia en el campo criminológico chileno, véase: Vetö (2015 y 2016). 
23. Sobre Greve Schlegel, véase: Ruperthuz (2014); Vezzetti (1996a); Freud (1987 y 1998a); Rosenthal (1945).

24. Para estudiar el impacto de las Jornadas Neuro-Psiquiátricas panamericanas en la neuro-psiquiatría chilena, véase: Araya Ibacache (2014 y 2015).

25. Esta serie: defecto - degeneración - vicio, es muy común en los escritos de médicos, profesores, visitadoras sociales, abogados y juristas, y políticos de la época. Respecto de ella, sólo nos interesa de momento destacar que no necesariamente es exclusivamente heredo-degeneracionista ni eugénica pura, dado que este paradigma se mezclaba con las perspectivas ambientalistas propias del higienismo, incluyendo el refuerzo del medio social ya sea para producir, ya sea para transmitir generacionalmente (degeneración) el defecto y convertirlo así en vicio.

26. Cabe destacar que en Chile antes de la década de 1950, las referencias no excluyentes a Freud y Adler, sobre todo en el contexto del trabajo con niños y adultos "antisociales", es sumamente frecuente, apareciendo en casi todas las fuentes primarias de la época.

27. Lo cual puede encontrarse expuesto en el libro de otro de los psiquiatras y psicoanalista de la Clínica de Conducta, el Dr. Ramón Clarés, titulado, Sobre la psicogénesis del arte. Tentativas, publicado en 1947.

28. El uso de la teoría de los complejos es también una característica de las apropiaciones del psicoanálisis en Chile en esta época, sobre todo aquellas realizadas en los campos de la criminología y del arte. Las principales referencias al respecto utilizadas por autores nacionales son los libros de los psicoanalistas franceses Charles Baudouin y Angelo Hesnard: El alma infantil y el psicoanálisis de Baudouin, publicada en francés en 1931 y editada en Chile alrededor de 1934 por Pax-Chile, y El individuo y el sexo, aparecido en Francia en 1927 y publicado por Editorial Ercilla en 1936. A partir de estas obras, sabemos que la teoría de los complejos no se remitía exclusivamente a aquello trabajado por Freud o por Jung, sino a los aportes de dichos otros autores, quienes -para bien o para mal-, dedicaron muchas páginas a la identificación y tipificación de distintos tipos de complejos.

29. Cabe advertir que en esa época en Chile no se utilizaba el concepto del "pulsión" para referirse a la noción freudiana de Trieb, sino el de "instinto", el cual se había popularizado ya en la década de 1920 a partir de la traducción de Freud por Luis López Ballesteros para la editorial Biblioteca Nueva, de Madrid.

30. Cubillos, además de trabajar en la Clínica de Conducta, era psiquiatra del Manicomio Nacional, de la Clínica Psiquiátrica
Universitaria de la Universidad de Chile, profesor de Biología Criminal en la Penitenciaría de Santiago y en la Escuela Técnica de Investigaciones y médico del Instituto de Clasificación y Criminología, fundado en 1936 en la Universidad de Chile. En 1935 había publicado un texto muy influyente en la criminología nacional de la época, titulado "Delincuencia: problema biológico-social y legal", que apareció por entregas en la recién fundada Revista de ciencias penales, y es demostrativo de las principales orientaciones de la medicina legal de la época (Cubillos, 1935a, 1935b y 1935c).

31. El número total de casos que aparecen repartidos en estas categorías es de 153, el cual lamentablemente no se corresponde ni con el número total de casos ingresados en el periodo, ni con el total de niños en tratamiento. A pesar de esta inconsistencia numérica, nos parece que otorgan una interesante perspectiva respecto de las categorías diagnósticas utilizadas y de la prevalencia detectada en ese momento entre los niños que llegaban a la Clínica de Conducta.

32. Siguiendo a Tirapegui (1925), podemos decir que en aqueIla época en Chile la inteligencia no es entendida como algo puramente orgánico ni hereditario, así como tampoco algo solamente ambiental. Retomando los postulados de WiIliam Stern, Hermann Ebbinghaus, Charles Spearman y por supuesto también de Alfred Binet, Tirapegui sostiene que la inteligencia es la capacidad de comprender una situación y adaptarse a las exigencias, a los nuevos problemas y condiciones, así como la capacidad de abstraer, comparar y contrastar. Tirapegui distingue además una "inteligencia general", que sería innata, y una "inteligencia adquirida", y sostiene que todo ser humano tiene una capacidad innata para aprender, y que son las condiciones ambientales las que permiten que dicha capacidad se desarrolle al máximo, o no lo haga.

33. Aquí, al igual que en la estadística referente a los diagnósticos, el número total de casos es 110 , el cual no corresponde con el número total de casos ingresados en el periodo, ni con el total de niños en tratamiento. A pesar de ello, insistimos en que nos parece instructivo aun así dar cuenta de los métodos de tratamiento más utilizados en la institución.

34. Es de vital importancia destacar que las fuentes utilizadas para este estudio implican ciertas restricciones a la hora de considerar las prácticas clínicas efectivamente ejercidas en la Clínica de Conducta. Dado que no contamos aún con ningún tipo de historiales clínicos, archivos ni expedientes de la Clínica, sólo podemos aludir a las nociones y representaciones que se tenía de la "anormalidad", la "desadaptación", las "conductas antisociales" en los niños. Hasta qué punto se aplicó y practicó aquello que se decía, debe ser estudiado y confrontado desde otro tipo de fuentes históricas que hasta el momento lamentablemente no hemos encontrado. 


\section{BIBLIOGRAFÍA}

Abarca, Gabriel y Winkler, María Inés (2013), “Rómulo Peña: reseña de la vida y obra de un profesor y pionero de la psicología", Boletín del Museo Regional de Atacama, 4 (4), pp. 129-147.

Agüero, Guillermo (1938), “Psiquiatría e higiene mental infantil, nuestra experiencia", Acción Social, VII (66), pp. 31-39.

Agüero, Guillermo y Gallinato, Alberto (1936), “Clínica de psicopatología infantil", Revista de educación, 80, pp. 3-8.

Agüero, Guillermo y Gallinato, Alberto (1937), "La Higiene Mental en nuestra Estructura Sanitaria (trabajo presentado en las Segundas Sanitarias Nacionales; Santiago, 1937)", Revista de Educación, VII (88), pp. s/n.

Agüero, Guillermo y Cubillos, Luis (1938), “Consideraciones sobre Clínicas de Higiene Mental Infantil y delincuencia de menores", Revista de Psiquiatría y Disciplinas Conexas, III (10), pp. 38-50.

Alarcón, Cristina (2010), El discurso pedagógico fundacional de docentes secundarios. Sobre la transferencia educativa alemana en Chile (1889-1910), Buenos Aires, Libros Libres Editores.

Allende, Salvador (2005), Higiene mental y delincuencia, Tesis para optar al título de Médico Cirujano de la Universidad de Chile (1933), Santiago, Fundación Presidente Allende (España) y Ediciones ChileAmérica/CESOC.

Araya Ibacache, Claudia (2014), “Inserción de las psiquiatrías nacionales en el contexto de consolidación de la modernización latinoamericana: Primeras Jornadas Neuro-Psiquiátricas Panamericanas, Santiago de Chile, 1937", Nuevo Mundo Mundos Nuevos, Sección Coloquios, [en línea], http:// dx.doi.org/10.4000/nuevomundo.66931

Araya Ibacache, Claudia (2015), Profesionalización de la psiquiatría en Chile: saberes y prácticas, 1826-1949, Tesis de Doctorado en Historia, Santiago, Universidad Católica de Chile.

Arce Molina, Baldomero (1937), Higiene mental, Santiago, Editorial Nascimento.

Barr-Melej, Patrick (2001), Reforming Chile: Cultural Politics, Nationalism, and the Rise of the Middle Class, Chapel Hill, The University of North Carolina Press.

Beers, Clifford W. (1908), A Mind that Found Itself: an Autobiography, New York, Longmans, Green and Co.

Caiceo, Jaime (2009). "Esbozo de la educacion especial en chile: 1850-1980", InterMeio: revista do Programa de Pós-Graduação em Educação, 15 (30), pp. 102-122.

Carnevali, Raúl (2008), “La ciencia penal italiana y su influencia en Chile", Política Criminal 6, pp. 1-19.
Carnevali, Raúl y Matus, Jean Pierre (2007), “Análisis descriptivo y cuantitativo de los artículos de Derecho penal y Criminología de autores chilenos en Revistas publicadas en Chile (1885-2006)", Política criminal, 3, pp. 1-138.

Chávez-García, Miroslava (2016), States of Delinquency: Race and Science in the Making of California's Juvenile Justice System, Berkeley, University of California Press.

Cillero, Miguel (1994), “Evolución histórica de la consideración jurídica de la infancia y adolescencia en Chile". En: Pilloti, Francisco (comp.), Infancia en riesgo y políticas sociales en Chile, Montevideo, Instituto Interamericano del Niño, pp. 223-250.

Cillero, Miguel (2001), “Los derechos del niño: de la proclamación a la protección efectiva", Justicia y derechos del niño, 3, pp. 49-63.

Clarés, Ramón (1947), Psicogénesis del arte. Tentativas, Santiago, Ediciones Seneca.

Couso, Javier (2000), "Los niños en los tiempos de los derechos". En: Dooner, P. y Medina, H. (eds.), Por los caminos de la esperanza, Santiago, SENAME, pp. 45-64.

Cubillos, Luis (1935a), "Delincuencia: problema biológico-social y legal", Revista de ciencias penales, I (1), pp. 146-153.

Cubillos, Luis (1935b), “Delincuencia: problema biológico-social y legal”, Revista de ciencias penales, I (3), pp. 324-332.

Cubillos, Luis (1935c), “Delincuencia: problema biológico-social y legal", Revista de ciencias penales, I (4), pp. 488-497.

Cunningham, Hugh (2005), Children and Childhood in Western Society since 1500, London, Longman.

Damousi, Joy (2005), Freud in the Antipodes: a Cultural History of Psychoanalysis in Australia, Sydney: University of South Wales Press.

Flores Muñoz, José (1932), Prueba mental de Myers, Santiago, Impr. Esc. Ciegos y Sordomudos.

Freud, Sigmund (1987), "Reseña y Comentarios de Freud al primer trabajo psicoanalítico chileno", Revista chilena de psicoanálisis 6 (1), pp. 3-4.

Freud, Sigmund (1998a), "Contribución a la historia del movimiento psicoanalítico (1914)". En: Obras completas, Vol. XIV, Buenos Aires, Amorrortu Editores, pp. 1-63.

Freud, Sigmund (1998b). "El malestar en la cultura (1929 [1930])". En: Obras completas, Vol. XXI, Buenos Aires, Amorrortu Editores, pp. 57-140.

Freud, Sigmund y Breuer, Joseph (1998). "Estudios sobre la histeria (1892-95 [1895])". En: Obras completas, Vol. II, Buenos Aires, Amorrortu Editores, pp. 1-309. 
Gajardo, Samuel (1929), Los derechos del niño y la tiranía del ambiente: divulgación de la ley 4.447: psicología, educación, derecho penal, Santiago, Nascimento.

Gajardo, Samuel (1940), Educación sexual del niño y del adolescente, Santiago, Editorial Chile.

Gallinato, Alberto (1941), "Influencia de la inteligencia sobre los trastornos de la conducta", Archivos Hospital de Niños Roberto del Río, X (2 y 3), pp. 124-132.

Galitzi, Christine (1937), "El servicio social psiquiátrico y la clínica de conducta en los Estados Unidos", Jornadas NeuroPsiquiátricas Panamericanas, pp. 613-617.

Gallo, Rubén (2013), Freud en México. Historia de la un delirio, México D.F., Fondo de Cultura Económica.

Garafulic, Juan y Lea-Plaza, Hugo (1936), “Profilaxis de las psico y neuropatías infantiles", Anales de la Facultad de Biología y Ciencias Médicas de la Universidad de Chile, I (2), pp. 293-315.

Garafulic, Juan (1955), "Evolución de la psiquiatría en Chile”, Revista de Neuropsiquiatría 20 (1), pp. 60-75.

Grob, Gerald (1987), Mental IIInes and American Society, 18751940, Princeton, Princeton University Press.

Hendrick, Harry (1997), Children, Childhood and English Society, 1880-1990, Cambridge, Cambridge University Press.

Hendrick, Harry (2005), Child Welfare and Social Policy: an Essential Reader, Bristol, Policy Press.

Illanes, María Angélica (2007), Cuerpo y sangre de la política: la construcción histórica de las visitadoras sociales, Chile, 1887-1940, Santiago, LOM Editores.

Illanes, María Angélica (2010), “En el nombre del pueblo, del Estado y de la ciencia, (...)": Historia social de la salud pública en Chile, 1880/1973 (Hacia una historia social del siglo XX), Santiago, Ministerio de Salud, Chile.

Iturriaga, Abelardo (1929), "La delincuencia juvenil”, Boletín de la Dirección General de Protección de Menores, I (1), pp. 16-33.

Iturriaga, Abelardo (1930), "Estudios de psicología experimental en los niños y jóvenes delincuentes", Boletín de la Dirección General de Protección de Menores, 1 (3), pp. 211-244.

Iturriaga, Abelardo (1935), "La inteligencia de los niños y jóvenes delincuentes", Boletín de la Dirección General de Protección de Menores, 3 (7), p. 733.

Laborda, Mario y Quezada, Vanetza (eds.) (2010), Notas históricas de la psicología en Chile, Santiago, Editorial Universitaria.

Lea-Plaza, Hugo (1929), “La Sección de Observación de la Casa de Menores de Santiago", Boletín de la Dirección General de Protección de Menores, I (1), pp. 11-15.
Lea-Plaza, Hugo (1934), “Observación y clasificación de los menores irregulares y las bases para su reeducación", 2 da conferencia Interamericana de Educación, Septiembre 1934, Tomo II, Temas oficiales, Santiago, Impr. Universidad de Chile, pp. 493-502.

León, Marco Antonio (2012), "Los dilemas de una sociedad cambiante: criminología, criminalidad y justicia en Chile contemporáneo (1911-1965)", Revista Chilena de Historia del Derecho, 19.

León, Marco Antonio y Rojas, Mauricio (2015), “Construyendo al futuro ser social: intervenciones médicas y pedagógicas en la infancia anormal. Santiago de Chile, 1920-1943", Asclepio, 67 (2), [en línea], http://dx.doi.org/10.3989/asclepio.2015.32

Mann, Wilhelm (1936), Chile. Luchando por nuevas formas de vida, Tomo II, Santiago, Editorial Ercilla.

Matus, Jean Pierre (2010), “La doctrina penal de la (fallida) recodificación chilena del Siglo XX y principios del XXI", Política Criminal, 5 (9), pp. 143-206.

Milanich, Nara B. (2009), Children of Fate. Childhood, Class, and the State in Chile, 1850-1930, Durham, Duke University Press.

Mülberger, Annette (2014), "The Need for Contextual Approaches to the History of Mental Testing", History of Psychology, 17 (3), pp. 177-186.

Pierre, Eric (2008), Les premiers juges des enfants en France. Entre roman des origines et contingences du quotidien: les apports de la base de données sur les juges des enfants. En: Bernaudeau, Vicent, Nandrin, Jean-Pierre, Rochet, Bénédicte, Rousseaux, Xavier y Tixhon, Axel (eds.), Les praticiens $d u$ droit du Moyen Âge à l'époque contemporaine. Approches prosopographiques (Belgique, Canada, France, Italie, Prusse), Rennes, Presses Universitaires de Rennes, pp. 335-341.

Platt, Anthony M. (2009), The Child Savers: The Invention of Delinquency, New Brunswick, Rutgers University Press.

Plotkin, Mariano Ben (2003), Freud en las pampas, Buenos Aires, Sudamericana.

Poblete, Manuel (1980), “A propósito del centenario de la Creación del Primer Laboratorio de Psicología Experimental, Revista Chilena de Psicología, 3(1), pp. 15-19.

Reyes, Leonora (2010), “Profesorado y trabajadores: Movimiento educacional, crisis educativa y reforma de 1928", Docencia, 40, pp. 40-49.

Richardson, Theresa R. (1989), The Century of the Child: the Mental Hygiene Movement and Social Policy in the United States and Canada, Albany, State University of New York Press.

Rojas Flores, Jorge (2010), Historia de la infancia en el Chile republicano, 1810-2010, Santiago, JUNJ.

Rosenthal, Ludovico (1945), "El psicoanálisis en la Argentina hace 35 años", Revista de psicoanálisis 3, pp. 202-203. 
Ruperthuz, Mariano (2014), “Germán Greve Schlegel y la recepción del psicoanálisisen Chile: la historia de un médico chileno 'probablemente alemán'", Universitas Psychologica, 13 (5), pp. 1847-1867.

Ruperthuz, Mariano (2016), Freud y los chilenos. Un viaje transnacional (1910-1949), Santiago, Editorial La Pólvora.

Ruperthuz, Mariano y Vetö, Silvana (2016), “El psicoanalista como personaje en las novelas de Juan Marín y Samuel Gajardo, Chile 1930-1940", Revista de Humanidades, 34, pp. 11-35.

Salas, Irma (1942), "La investigación pedagógica en Chile", Anales de la Universidad de Chile, 45-46, año 100, pp. 113-134.

Salas, Gonzalo (2012), "La influencia europea en los inicios de la historia de la psicología en Chile", Revista Interamericana de Psicología 46 (1), pp. 99-110.

Salas, Gonzalo y Lizama, Eugenio (2009), Historia de la psicología en Chile, 1889-1981, La Serena, Editorial Universidad de La Serena.

Sandoval Carrasco, Juan (1941), El niño retardado mental, Santiago, Publicaciones Escuela Especial de Desarrollo.

Sanhueza, Carlos (2013), “La gestación del Instituto Pedagógico de Santiago y la movilidad del saber germano a Chile a comienzos del siglo XIX", Estudos Ibero-Americanos, 39 (1), PUCRS, pp. 54-81.

Serrano, Sol, Ponce de León, Macarena y Rengifo, Francisca (2012), Historia de la educación en Chile (1810-2010), Santiago, Editorial Taurus.

Shamdasani, Sonu (2005), "'Psychotherapy': the invention of a word", History of the Human Sciences 18 (1), pp. 1-22.

Sommerville, John (1990), The Rise and Fall of Childhood, New York, Vintage Books.

Stagno, Leandro (2011), "Los Tribunales de Menores en la Argentina. Antecedentes internacionales e iniciativas nacionales (19331943)". En: Cosse, Isabella, Llobet, Valeria, Villalta, Carla y Zapiola, María Carolina (eds.), Infancias: políticas y saberes en Argentina y Brasil. Siglos XIX y XX, Buenos Aires, Teseo, pp. 335-365.

Talak, Ana María (2005), "Eugenesia e higiene mental: usos de la psicología en la Argentina, 1900-1940”. En: Miranda, Marisa y Vallejo, Gustavo (comps.), Darwinismo social y eugenesia en el mundo latino, Buenos Aires, Siglo XXI, pp. 563-599.

Tanenhaus, David S. (2004), Juvenile Justice in the Making, Oxford, Oxford University Press.

Tirapegui, Luis Alberto (1925), “El desarrollo de la intelijencia medido por el método Binet-Simon", Anales de la Universidad de Chile 3 (Julio-Septiembre, Serie 2), pp. 453-591.
Tirapegui, Luis Alberto (1941), Test de Kohs para el examen de la inteligencia, Santiago, Talleres Gráficos Casa Nacional del Niño.

Toledo, Ida y Zúñiga, Lina (1991), Defensa de los derechos del niño: antecedentes históricos desde la perspectiva de Chile, Santiago, Fundación PIDEE.

Vetö, Silvana (2015), "Psicoanálisis y eugenesia en el campo criminológico chileno de la década de 1930 y 1940: indagaciones a partir de algunos escritos del Juez de Menores Samuel Gajardo". En: Leyton, César, Palacios, Cristián y Sánchez, Marcelo (eds.), El bulevar de los pobres. Racismo científico, higiene y eugenesia en Chile e Iberoamérica siglos XIX y XX, Santiago, Ocho Libros Editores, pp. 163-193.

Vetö, Silvana (2016), "Un saber de lo cotidiano: circulación del psicoanálisis en Chile en revistas culturales en la primera mitad del siglo XX". En: Correa, María José, Kottow, Andrea y Vetö, Silvana (eds.), Ciencia y espectáculo. Circulación de saberes científicos en América Latina, siglos XIX y XX, Santiago, Ocho Libros Editores, pp. 245-276.

Vetö, Silvana y Sánchez, Marcelo (2017), "Sigmund Freud and Alejandro Lipschütz: Psychoanalysis and biology, between Europe and Chile", History of the Human Sciences 30 (1), pp. 7-31

Vezzetti, Hugo (1996a), Freud en Buenos Aires. 1910-1939, Bernal, Universidad Nacional de Quilmes.

Vezzetti, Hugo (1996b), Aventuras de Freud en el país de los argentinos: De José Ingenieros a Enrique Pichón-Rivière, Buenos Aires, Paidós.

Vigarello, Georges (2005), "L'intolérable de la maltraitance infantile. Genèse de la loi sur la protection des enfants maltraités et moralement abandonnés en France". En: Fassin, Didier y Bourdelais, Patrice (dirs.), Les constructions de l'intolérable. Etudes d'anthropologie et d'histoire sur les frontières de l'espace moral, Paris, Editions La Découverte, pp. 111-127.

Winkler, María Inés (2007), Pioneras sin monumentos. Pioneras en psicología, Santiago, LOM Ediciones.

Yepsen, Lloyd. N. (1930), "El problema de los débiles mentales", Revista chilena de pediatría, 10 (Octubre), pp. 507-531.

Zárate, María Soledad (comp.) (2008), Por la salud del cuerpo: historia y políticas sanitarias en Chile, Santiago, Universidad Alberto Hurtado.

Zaretsky, Eli (2012), Secretos del alma: una historia social y cultural del psicoanálisis, Madrid, Siglo XXI.

Zelizer, Viviana A. (1994), Pricing the Priceless Child. The Changing Social Value of Children, New Jersey, Princeton University Press. 